\title{
Comparative Analysis of Women With Notable Subjective Health Indicators Compared With Participants in the Australian Longitudinal Study on Women's Health: Cross-Sectional Survey
}

Christoph Schnelle ${ }^{1}$, MBiostats; Eunice J Minford ${ }^{2}$, MA, MBChB, FRCSEd; Vanessa McHardy ${ }^{3}$, MA; Jane Keep ${ }^{4}$, $\mathrm{PhD}$

\footnotetext{
${ }^{1}$ School of Public Health, Faculty of Medicine, University of Queensland, Herston, Queenland, Australia

${ }^{2}$ Faculty of Medicine, Health and Life Sciences, Queen's University Belfast, Antrim, Ireland

${ }^{3}$ Light Education Training Ltd, London, United Kingdom

${ }^{4}$ The Leaders Leader, Greater London, United Kingdom
}

\section{Corresponding Author:}

Christoph Schnelle, MBiostats

School of Public Health

Faculty of Medicine

University of Queensland

Herston Road

Herston, Queenland, 2480

Australia

Phone: 61266244242

Fax: 61266191033

Email: christoph.schnelle@uq.net.au

\section{Related Articles:}

This is a corrected version. See correction statement in: http://publichealth.jmir.org/2018/2/e53/

This is a corrected version. See correction statement in: https://publichealth.jmir.org/2019/3/e16314

\section{Abstract}

Background: At least six communities with unusually good health and longevity have been identified, but their lifestyles aren't adopted widely. Informal evidence suggests that women associated with Universal Medicine (UM), a complementary medicine health care organization in Eastern Australia and the United Kingdom with normal lifestyles, also have several unusual health indicators.

Objective: Our objective was to determine how UM participants compared with women in the Australian population at large on a variety of health indicators.

Methods: In an Internet survey conducted July to September 2015, a total of 449 female UM participants from 15 countries responded to 43 health indicator questions taken from the Australian Longitudinal Study on Women's Health (ALSWH).

Results: Survey responses revealed large positive differences in mental and physical health when compared with the ALSWH respondents, except for abnormal Pap test and low iron history. Differences and corresponding effect size estimates (Cohen $d$; $\geq 0.8$ is a high difference, $\geq 0.5$ a medium and $\geq 0.2$ a small one with $P<.001$ except where indicated) included body mass index (BMI; 1.11), stress level $(0.20, P=.006)$, depression $(0.44)$, summary physical $(0.31)$ and mental health $(0.37)$, general mental health (0.39), emotional $(0.15, P=.009)$ and social functioning $(0.22)$, vitality $(0.58)$, and general health $(0.49)$, as well as lower incidences of diabetes, hypertension, and thrombosis $(P<.001$ each). Neither education levels nor country of residence had predictive value. Age did not predict BMI.

Conclusions: The women's responses notably claim substantially lower levels of illness and disease than in the general Australian population.

Trial Registration: Australian New Zealand Clinical Trials Registry (ANZCTR): ACTRN12617000972325; https://www.anzctr. org.au/Trial/Registration/TrialReview.aspx?id=373120\&isReview=true (Archived by WebCite at http://www.webcitation.org/ 6wEDDn450)

International Registered Report Identifier (IRRID)： DERR2-10.2196/7993 
(JMIR Public Health Surveill 2018;4(1):e6) doi: 10.2196/publichealth.9490

\section{KEYWORDS}

women's health; health surveys; public health; Australian Longitudinal Study on Women's Health; ALSWH; Universal Medicine; preventive medicine; health care costs; complementary therapies; cross-sectional studies

\section{Introduction}

The population in the developed world is getting both older and, even after accounting for age, less healthy. Increasing morbidity and the associated rise in health care costs [1-4], especially for diabetes and obesity [5-8], present serious and ever-growing societal challenges.

There have always been individuals who live exceptionally healthy lives, but entire communities that demonstrate superior health are rare; 4 such groups are the residents of the small US Pennsylvanian town of Roseto [9], Seventh Day Adventists [10], traditional Japanese [11], and senior Whitehall (UK) civil servants [12]. However, their lifestyles have not been adopted widely.

We report a survey of a group of people, primarily women, who form a community that is scattered throughout the world. The unifying characteristic is participation in an organization called Universal Medicine (UM), as described below. Informal evidence that can be gathered by visiting any UM-run event shows a low number of overweight or obese participants present, even though most events do not involve physical activity and few members profess to be on weight loss diets at any time. In addition, older participants seem not to have a higher body mass index (BMI) than younger participants.

\section{Methods}

\section{Participants}

Of all UM participants, $76 \%$ are female; therefore, for this initial investigation, we chose to focus on comparing the health of women in UM with that of a larger female population. For comparison, we adopted a substantial portion of questions from the Australian Longitudinal Study on Women's Health (ALSWH). The ALSWH survey was inaugurated in 1996 and includes data from approximately 75,000 women [13-16].

We designed this study to answer the following questions. (1) Do women who participate in UM appear to have overall health substantially different from that of the general female population, as represented by ALSWH respondents? (2) In which specific aspects of health do UM participants differ, and in which aspects are there no differences? (3) Is UM participants' health correlated with age, education, or their country of residence?

\section{Universal Medicine}

UM is a complementary medicine health care organization founded in 1999 near Lismore, in Eastern Australia. UM has approximately 200 male and 500 female regular attendees at its workshops and conferences. We drew the study sample from these regular participants.
Information on the UM website [17] describes the organization as follows:

\section{Universal Medicine is committed to providing Complementary Health \& Healing Services that are Universal [sic] in their approach towards medicine and healing.}

Through practical philosophies that inspire more self-caring and self-loving choices in daily life, Universal Medicine supports people to explore their overall well-being, the development of energetic awareness, and the depth they can bring to their quality of life and relationships.

Teachings are delivered in the form of lectures, talks, audios and treatments from Universal Medicine clinics. [It] regularly holds courses, workshops and retreats throughout Australia and internationally.

This survey is the first scientific investigation to look at the health of the UM participants.

UM has developed several treatment modalities. One such modality, called Esoteric Connective Tissue Therapy, is being studied in a randomized controlled trial on chronic low back pain [18]. These treatment modalities were used by $99.7 \%$ (367/368) of UM respondents in the 12 months prior to taking the survey.

Like other institutions that support self-empowerment of women, such as the family court, women's shelters, and social services, UM has been the target of criticism in the form of "a vigorous, determined campaign" [19] by a small number of detractors. In contrast, at least 34 registered medical professionals are among the regular visitors to UM events. The curious coexistence of harsh critics, medical professional advocates, and anecdotal evidence of substantial benefit could make UM an interesting object of study.

\section{General Characteristics of the UM Survey and its Relationship to the ALSWH}

The full UM survey comprised 43 questions from the ALSWH, as well as a newly developed menstrual attitudes questionnaire; the latter is not discussed in this paper. We chose the ALSWH items to maximize comparability of the 2 groups. For comparisons, we used the electronic ALSWH data books [20], which give frequencies, mean scores, and, in some cases, standard deviations.

The ALSWH website [21] states that the ALSWH is

... a longitudinal survey of over 58,000 women in three cohorts who were aged 18-23 (the 1973-1978 cohort), 45-50 (the 1946-1951 cohort), and 70-75 when surveys began in 1996....ALSWH assesses women's physical and mental health, as well as psychosocial 
aspects of health (such as socio-demographic and lifestyle factors) and their use of health services.

An additional 17,000 participants were added after the definition was written.

\section{Study Population}

Our study population of interest comprised 500 UM-participating women who, although they were consumers of complementary medical services, had profiles that differed in important ways from those of typical complementary medicine adherents [22]: UM participants, as recorded in this survey, did not have poorer health or a higher use of registered medical professionals (nor was their use substantially lower) than the ALSWH respondents. One difference is that UM women were more likely to be middle-aged.

\section{Design, Privacy of Data, and Recruitment}

The portion of the data collection that was relevant to this study was a quantitative, cross-sectional online survey of women's health. We did not collect any directly identifying data; however, we did collect indirectly identifying data such as partial medical history and age in years. Due to privacy considerations, portions of the data will not be available for inclusion in a public repository. We present age as a range, and we exclude the medical history data.

We recruited participants via 2 overlapping mailing lists of 650 and $350 \mathrm{UM}$ members, and by distributing flyers at several UM-sponsored events in 2015.

Ethical approval was given by the University of Queensland School of Public Health Research Ethics Committee on June 23, 2015 (CS23062015). The first item on the survey explained the purpose of the survey and asked participants to either grant their consent or decline to do so. The study is registered with the Australian New Zealand Clinical Trials Registry (ACTRN12617000972325). Multimedia Appendix 1 shows a Strengthening the Reporting of Observational Studies in Epidemiology (STROBE) checklist.

Deidentified data will be made available from the corresponding author on reasonable request. Data will not include potential identifiers, as outlined by Hrynaszkiewicz et al [23]. Specifically, this means that age will be categorized into intervals, and a list of medical procedures undergone and major illnesses will be excluded. Regrettably, the data cannot be shared in a public repository, as with such a small group, it would be relatively easy to identify individuals even with the above measures taken.

\section{Implementation}

The survey was completed online in July to September 2015, using the Survs survey platform (Enough Pepper Lda). In the case of duplicates, we removed 1 of them.

\section{Data Analysis}

We conducted informal focus groups with UM-participating women to help us identify the ALSWH items that seemed most relevant for comparison in this preliminary study, and not to exceed an average of 75 minutes in response time. Demographic items related to age, BMI, menstrual status, education, and lifestyle questions about smoking, alcohol use, number of general practitioner visits, and number of UM event visits were included. In addition to the 36-Item Short Form Survey (SF-36) [24], other standardized scales we incorporated were the Center for Epidemiologic Studies Depression Scale (CES-D) [25,26], Perceived Control Scale [27,28], and an ALSWH-developed multi-item summed score for perceived stress [14,29]. A further 6 items solicited information about sleep quality, 47 past diagnoses of medical issues, and frequency of 24 physical symptoms in the previous 12 months, with response options being "often," "sometimes," "rarely," and "never."

Of the ALSWH questions, 27 were asked twice, once with reference to the present, and once with reference to the time of the respondent's first attendance at a UM event.

\section{Adjusting for Age and Cohort}

The ALSWH age data from the data books [20] consisted of frequencies, means, and standard deviations. Individual data were not available. The ALSWH longitudinal study consists of surveys that are typically administered every 3 years, with numerous changes made to the items from one administration to the next. The results for 15 surveys of 3 age cohorts, born in 1921-1926, 1946-1951, and 1973-1978 have been published.

Because the ALSWH questions can change from one administration to the next, for each particular UM survey question, not all 15 ALSWH surveys included a comparable question.

We calculated the adjusted UM group responses for each variable by first excluding all UM respondents with an age that was not covered by an ALSWH survey. For example, in the question asking about past skin cancer diagnoses, we calculated the UM rate from only the 69 respondents aged 45 to 50 years and the 6 respondents aged 70 to 75 years.

The weighted ALSWH data are weighted by the frequency of UM respondents for that age group. For example, a question about any skin cancer diagnosis in the past was used in 2 ALSWH surveys: the first ALSWH survey of the 1946-1951 cohort with respondents aged 45 to 50 years, and the first ALSWH survey with respondents born between 1921 and 1926 and aged 70 to 75 years. There were $69 \mathrm{UM}$ respondents aged 45 to 50 years and 6 UM group respondents aged 70 to 75 years who gave valid responses; hence, the frequency weights used to calculate the weighted ALSWH skin cancer percentage (11.9\%) were 69 and 6 . This makes the UM results comparable with the ALSWH weighted results in terms of age.

\section{Adjusting for Education}

Age was a major predictor of the responses to many questions, but education turned out to have no predictive value. Hence, we did not adjust the data for education.

\section{Effect Size Calculations}

We calculated Cohen $d$ using the Stata command esizei (version 14.2; StataCorp LLC). The ALSWH standard deviations are reported to only 1 significant digit, so we assumed the maximum possible standard deviation (eg, 0.1 became 0.149 and 0.0 
became 0.049, reducing Cohen $d$ ), from which we used the pooled standard deviation [30] with Welch's approximation.

A superior approach for calculating $P$ values and effect sizes would be to compare the UM respondents with their closest ALSWH counterparts, taking account of age, education, and BMI. When the full ALSWH data are available, we will take this approach.

\section{Results}

\section{Survey Responses}

This survey produced 449 responses, of which 373 (83.1\%) were complete. The respondents answered from 17 countries (Australia, n=273; United Kingdom, n=97; Germany, n=26; the
Netherlands, $\mathrm{n}=11$; other European countries, $\mathrm{n}=18$; United States, $n=11$; rest of the world, $n=13$ ). Of the respondents, 13 did not consent, 3 were male, 20 did not give their menses status, 5 were less than 18 years of age, and 1 completed the survey twice, leaving 407 valid and 338 completed responses (Figure 1).

Table 1 and Table 2 show demographic and survey administration data. The UM group was more highly educated than the ALSWH cohort. The average UM group survey respondent's age was 48 (range 18-86) years; age was normally distributed (Shapiro-Wilk $P=.42$ ). The proportion of smokers among UM women was $1.6 \%$ (4/240), compared with $13.9 \%$ among ALSWH women. The rate of alcohol use among UM women was $1.8 \%(6 / 338)$ versus $86.3 \%$ for ALSWH women. 
Figure 1. Recruitment flowchart for participants in the Universal Medicine survey.

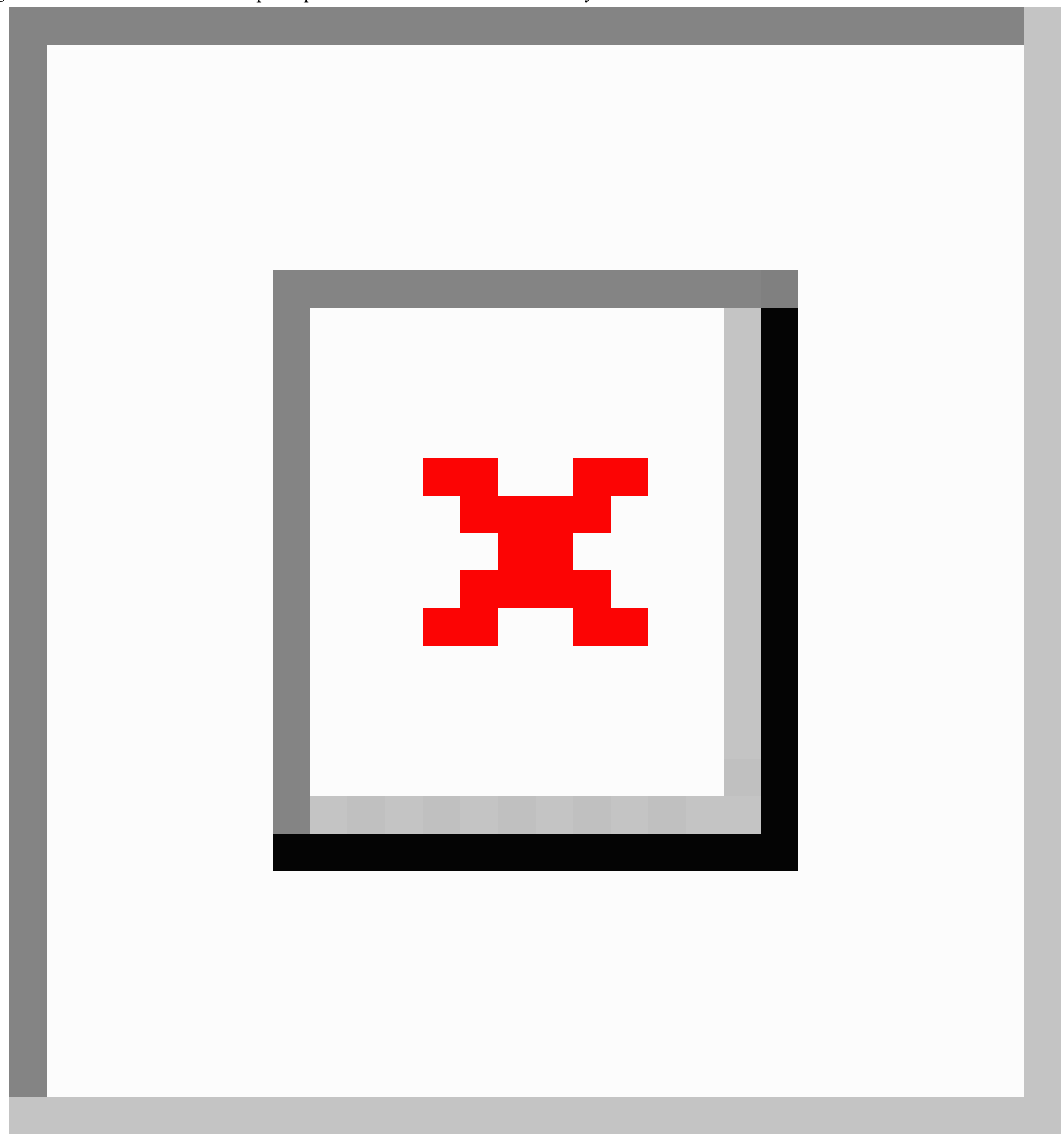


Table 1. Demographic and survey administration data for Universal Medicine (UM) participants compared with data from the Australian Longitudinal Study on Women's Health (ALSWH).

\begin{tabular}{ll}
\hline Characteristics & UM cohor \\
\hline Menstrual status & \\
Total $^{\mathrm{b}}$ & 407 \\
Menses & $173(42.5)$ \\
Perimenopausal & $75(18.4)$ \\
Menopausal & $159(39.1)$
\end{tabular}

Educational attainment

Total $^{\mathrm{b}}$

193

No formal education

$12(6.2)$

11.4

School certificate

$3(1.6)$

21.2

High school

$21(10.9)$

19.4

Trade, certificate, or diploma

$71(36.8)$

Degree

$66(34.2)$

17.3

Higher degree

$20(10.4)$

9.8

Number of UM events attended per year by survey participants

$0-1$

$2-5$

6-10

$\geq 11$

General practitioner visits

Total $^{\mathrm{b}}$

None

1-2

3-4

5-6

$\geq 7$

Smoking

Total $^{\mathrm{b}}$

Not at all

Less than weekly

Weekly

Daily

Alcohol consumption (drinks)

Total $^{\mathrm{b}}$

Daily

1-6/week

$<1 /$ week

Not for a year

Not for 5 years

Never
$1(0.25)$

54 (13.3)

81 (19.9)

$271(66.6)$

$<.001$

275

27 (9.8)

6.6

134 (48.7)

33.6

63 (22.9)

28.6

$31(11.3)$

15.9

$20(7.3)$

15.3

$<.001$

240

$236(98.3)$

86.2

$2(0.8)$

1.7

$0(0.0)$

1.2

$2(0.8)$

11.0

$<.001$
338

$\begin{array}{ll}1(0.3) & 6.5 \\ 0(0.0) & 36.8 \\ 5(1.5) & 42.8 \\ 38(11.2) & \\ 294(87.0) & \end{array}$

$P$ value \\ 01
}

(n)


${ }^{\mathrm{b}}$ Number of UM respondents with ages that were surveyed in ALSWH for this particular question. Example: skin cancer was covered in ALSWH Mid 1 (45-50 years old) and Old 1 (73-78 years old) surveys; UM group had 69 respondents aged 45-50 years and 6 aged 73-78 years who gave valid responses; 4 of the $69+6=75$ had skin cancer.

Table 2. Continuous demographic variables for Universal Medicine (UM) participants.

\begin{tabular}{|c|c|c|c|c|c|c|c|c|}
\hline \multirow[t]{2}{*}{ Continuous variables } & \multirow[t]{2}{*}{$\mathrm{n}$} & \multirow[t]{2}{*}{ Mean } & \multirow[t]{2}{*}{$\mathrm{SD}^{\mathrm{a}}$} & \multirow[t]{2}{*}{ Median } & \multicolumn{2}{|l|}{ Range } & \multicolumn{2}{|c|}{ Interquartile range } \\
\hline & & & & & Minimum & Maximum & $25 \%$ & $75 \%$ \\
\hline Age (years) & 407 & 47.7 & 11.8 & 47 & 18 & 86 & 40 & 56 \\
\hline Years with UM & 392 & 7.9 & 3.3 & 8.0 & 0.5 & 15.6 & 5.2 & 10.1 \\
\hline Body mass index $\left(\mathrm{kg} / \mathrm{m}^{2}\right)$ & 323 & 21.0 & 3.0 & 20.6 & 15.2 & 39.0 & 19.1 & 22.4 \\
\hline Age at menopause (years) & 137 & 49.9 & 5.1 & 50 & 27 & 58 & 47 & 52 \\
\hline Age at menstruation (years) & 338 & 13.1 & 1.6 & 13 & 9 & 19 & 12 & 14 \\
\hline
\end{tabular}

${ }^{\mathrm{a}} \mathrm{SD}$ : standard deviation.

The UM respondents' average BMI of $21.0 \mathrm{~kg} / \mathrm{m}^{2}$ was substantially lower than the ALSWH weighted BMI of 26.1 $\mathrm{kg} / \mathrm{m}^{2}$ (see Table 3). A regression analysis showed that the BMI for the UM respondents was related to neither education $(P=.63)$ nor age $(P=.56)$, in contrast to data from the ALSWH and the Australian Bureau of Statistics showing obesity rates increasing to ages 55-64 (men) and 65-74 (women) [31]. A fractional polynomial graph (a visual means for determining whether a relationship is linear or, for example, U-shaped) of age and BMI shows an almost straight horizontal line; that is, there is no apparent relationship (Figure 2).

Table 3 shows the lower BMI scores for UM respondents. UM responses scored higher (better) on the 4 common psychological health scales that measure stress, the level of perceived control, depression, and the mental and physical health scales of the SF-36.

Table 4 compares the proportion of UM respondents who reported ever having had a particular health issue (including the time before they became associated with UM) with weighted ALSWH responses. The UM respondents had substantially higher rates than the ALSWH group of abnormal Pap tests and diagnoses of low iron, and substantially lower rates of diabetes, hypertension, and thrombosis.

$P$ values use Pearson chi-square for the hypothesis that the rows and columns in the 2-way listing of UM respondents and ALSWH respondents in Table 4 are independent.

UM respondents had fewer sleep issues than did ALSWH respondents, with $68.9 \%$ (228/331) of the former and $27.9 \%$ of the latter reporting no issues at all. For lying awake most of the night, the percentages were $2.4 \%$ (UM, 8/331) versus $14.2 \%$ (ALSWH); taking a long time to get to sleep $(38 / 331,11.5 \%$ vs $28.8 \%$ ), being kept awake by worrying $(28 / 331,8.5 \%$ vs $18.9 \%)$, and sleeping badly at night $(44 / 331,13.3 \%$ vs $35.2 \%)$ (Multimedia Appendix 2).

Multimedia Appendix 3 shows the symptoms for which the UM respondents were noticeably different (in all cases noticeably fewer incidences) from their ALSWH counterparts. The lower rates of back pain, allergies, breathing difficulties, depression, panic attacks, headaches, migraines, hot flashes, and night sweats could be of interest (Figure 3).

We detected no difference of any substance for an effect of education, including BMI, Stress Scale, Perceived Control Scale, CES-D, and SF-36. Multimedia Appendix 4 shows this in graphical form.

UM survey responses scored more highly than ALSWH responses on composite physical and mental health (see Figure 4). For ALSWH respondents, physical scores peaked at age 18 to 23 years and mental scores peaked at age 73 to 78 years. UM survey respondents' scores were similar to peak ALSWH scores; that is, UM respondents had the higher physical scores of the very young and the higher mental scores of the very old.

\section{Effect Sizes}

Observed effect sizes (Cohen $d$ ) ranged from 0.6 to 11.9 (Table 3 ). These values are with one exception higher than the 0.8 considered to denote a large effect $[33,34]$.

\section{Linking UM Participation to Outcomes: Preliminary Exploration}

A cross-sectional survey is not able to establish causality, so it is possible that participants for whom UM events held appeal were already healthier. However, there are indications in the data that this was not the case. The UM survey asked respondents to answer 27 of the 43 ALSWH questions as per their memory of how they were feeling at the time of their first UM event and to answer the same questions in relation to the present. Multimedia Appendix 2 shows BMI changes. Retrospective reports are always subject to the vagaries of memory and have low reliability, but until a prospective longitudinal study is undertaken, these data are the best available. The data indicate the UM respondents were of average or below-average physical health and below-average mental health at the time of their first UM event. Examples are the proportion who often had back pain in the previous 12 months: $25.8 \%$ (UM past, 87/337) versus 3.3\% (UM present, 11/336) versus $17.8 \%$ (ALSWH); those who had depression: $18.3 \%$ $(61 / 333)$ versus $0.6 \%(2 / 332)$ versus $6.6 \%$; and those who had allergies: $26.0 \%(86 / 331)$ versus $0.9 \%(3 / 332)$ versus $14.9 \%$. 
Table 3. Results from standard survey scales in the Australian Longitudinal Study on Women's Health (ALSWH) and Universal Medicine (UM) groups, with $r$ values and standard deviation.

\begin{tabular}{|c|c|c|c|c|c|c|c|c|c|c|c|}
\hline & \multicolumn{4}{|c|}{$\begin{array}{l}\text { Survey respondents with ages covered by } \\
\text { ALSWH surveys }\end{array}$} & \multicolumn{3}{|c|}{$\begin{array}{l}\text { ALSWH respondents with UM } \\
\text { frequency weights }\end{array}$} & \multicolumn{4}{|c|}{ Effect size } \\
\hline & $\mathrm{n}^{\mathrm{a}}$ & Mean & $95 \% \mathrm{CI}$ & $\mathrm{SD}^{\mathrm{b}}$ & Mean & $95 \% \mathrm{CI}$ & $\mathrm{SD}^{\mathrm{b}}$ & Cohen & $95 \% \mathrm{CI}$ & $r^{\mathrm{c}}$ & $p c$ \\
\hline Body mass index $\left(\mathrm{kg} / \mathrm{m}^{2}\right)$ & 253 & 21.0 & $20.7-21.4$ & 2.97 & 26.1 & $25.9-26.2$ & 4.6 & 1.11 & $0.98-1.23$ & .48 & $4 * 10^{-66}$ \\
\hline Stress $^{\mathrm{d}}$ (lower is better) & 200 & 0.63 & $0.55-0.70$ & 0.52 & 0.73 & $0.72-0.75$ & 0.53 & 0.20 & $0.057-0.38$ & .10 & 0.0059 \\
\hline Perceived Control Scale ${ }^{\mathrm{d}}$ & 135 & 4.9 & $4.8-5.0$ & 0.63 & 4.3 & $4.3-4.3$ & 0.79 & 0.74 & $0.57-0.91$ & .35 & $2 * 10^{-17}$ \\
\hline CES-D ${ }^{\mathrm{d}}$ (lower is better) & 233 & 3.6 & $3.1-4.2$ & 5.60 & 6.1 & $6.1-6.2$ & 5.6 & 0.44 & $0.31-0.57$ & .21 & $6 * 10^{-11}$ \\
\hline \multicolumn{12}{|l|}{$S F-36^{d}$} \\
\hline $\begin{array}{l}\text { Summary Physical } \\
\text { Health }\end{array}$ & 272 & 52.8 & $51.9-53.6$ & 10.0 & 49.7 & $49.4-49.9$ & 10.0 & 0.31 & $0.19-0.43$ & .15 & $6 * 10^{-7}$ \\
\hline $\begin{array}{l}\text { Summary Mental } \\
\text { Health }\end{array}$ & 272 & 51.4 & $50.4-52.5$ & 10.0 & 47.7 & $47.5-47.9$ & 10.0 & 0.37 & $0.25-0.50$ & .18 & $10^{-9}$ \\
\hline $\begin{array}{l}\text { General Mental } \\
\text { Health }\end{array}$ & 295 & 80.1 & $78.5-81.7$ & 13.6 & 73.2 & $72.9-73.4$ & 17.9 & 0.39 & $0.27-0.51$ & .19 & $5 * 10^{-11}$ \\
\hline Role Emotional & 294 & 85.3 & $82.2-88.3$ & 26.5 & 79.6 & $79.2-79.9$ & 36.9 & 0.15 & $0.038-0.27$ & .08 & 0.0091 \\
\hline Social Functioning & 295 & 87.1 & $84.9-89.3$ & 19.1 & 81.9 & $81.7-82.1$ & 24.0 & 0.22 & $0.10-0.33$ & .11 & 0.0002 \\
\hline Vitality & 295 & 69.5 & $67.6-71.5$ & 17.2 & 57.5 & $57.2-57.8$ & 20.7 & 0.58 & $0.47-0.70$ & .28 & $9 * 10^{-23}$ \\
\hline General Health & 275 & 81.9 & $80.0-83.8$ & 15.9 & 71.8 & $71.6-71.9$ & 20.9 & 0.49 & $0.36-0.61$ & .24 & $3 * 10^{-15}$ \\
\hline Bodily Pain & 294 & 82.8 & $80.6-85.0$ & 19.5 & 70.7 & $70.4-70.9$ & 24.0 & 0.51 & $0.39-0.62$ & .25 & $2 * 10^{-17}$ \\
\hline Role Physical & 294 & 84.8 & $81.6-88.0$ & 27.9 & 78.2 & 77.9-78.6 & 36.2 & 0.18 & $0.10-0.34$ & .09 & 0.0019 \\
\hline Physical Function & 294 & 89.5 & 87.9-91.0 & 13.3 & 84.6 & $84.1-85.1$ & 19.7 & 0.25 & $0.16-0.40$ & .12 & 0.00003 \\
\hline
\end{tabular}

${ }^{\mathrm{a}}$ Number of UM respondents with ages that were surveyed in ALSWH for this particular question.

${ }^{\mathrm{b}} \mathrm{SD}$ : standard deviation.

${ }^{\mathrm{c}}$ The $\mathrm{r}$ value was calculated as $\mathrm{r}=\mathrm{d} /\left(\operatorname{sqrt}\left[4+\mathrm{d}^{2}\right]\right)$, where $d$ is Cohen $d$ as derived from the formula given by Nakagawa and Cuthill [32]. $P$ value calculated with Satterthwaite's $t$ test.

${ }^{\mathrm{d}}$ Multi-item summed scores for perceived stress, Perceived Control Scale, Center for Epidemiologic Studies Depression Scale (CES-D), and 36-Item Short Form Survey (SF-36) using Australian coefficients. 
Figure 2. Distribution of body mass index (BMI) by age of participants using fractional polynomial line of best fit including $95 \%$ CI. Note that the line is almost straight; that is, there is almost no association between BMI and age. In the general population, BMI rises with age up to 69 years (source: Australian Bureau of Statistics).

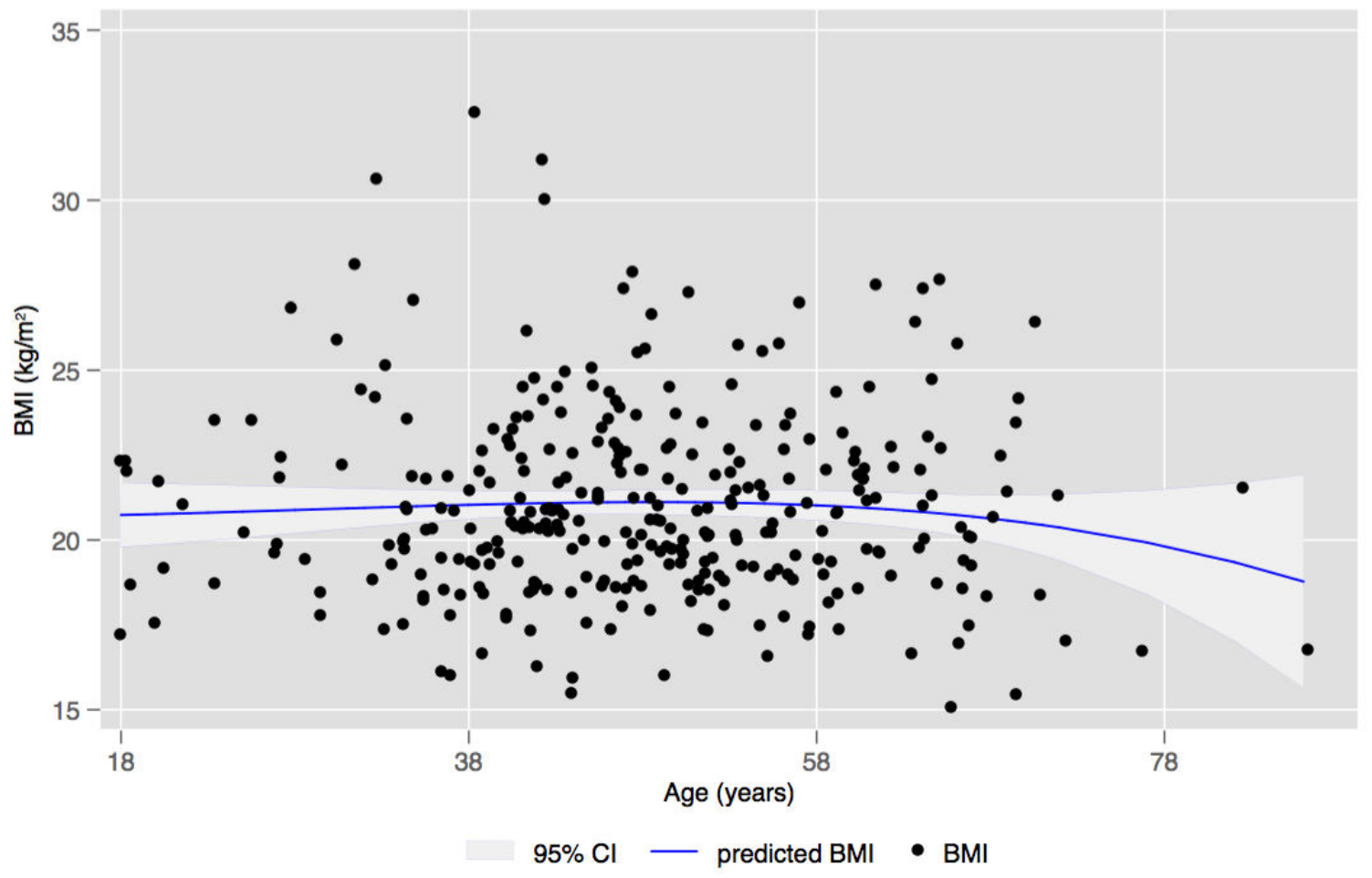


Table 4. Reported diagnoses among Universal Medicine (UM) and Australian Longitudinal Study on Women's Health (ALSWH) respondents.

\begin{tabular}{|c|c|c|c|c|}
\hline \multirow[t]{2}{*}{ Have you ever been diagnosed with: } & \multicolumn{2}{|c|}{ UM response "yes" (ALSWH ages $\left.{ }^{\mathrm{a}}\right)$} & \multirow[t]{2}{*}{ ALSWH $^{\mathrm{b}}$ weighted $(\%)$} & \multirow[t]{2}{*}{$P$ value } \\
\hline & $\mathrm{n}$ & $\%$ & & \\
\hline \multicolumn{5}{|l|}{ UM worse than ALSWH } \\
\hline Abnormal Pap test & 73 & 35.3 & 22.2 & $<.001$ \\
\hline Low iron & 38 & 41.3 & 29.8 & .02 \\
\hline \multicolumn{5}{|l|}{ No significant difference } \\
\hline Abnormal mammogram & 38 & 22.0 & 17.8 & .16 \\
\hline Asthma & 13 & 15.1 & 16.6 & .71 \\
\hline Bronchitis or emphysema & 14 & 18.7 & 18.9 & .96 \\
\hline Breast cancer & 2 & 2.7 & 2.4 & .88 \\
\hline Cervical cancer & 3 & 4.0 & 3.1 & .66 \\
\hline Heart disease & 2 & 2.2 & 2.8 & .72 \\
\hline Osteoporosis & 6 & 8.0 & 5.6 & .37 \\
\hline Skin cancer & 4 & 5.3 & 11.9 & .08 \\
\hline Stroke & 0 & 0.0 & 1.2 & .34 \\
\hline \multicolumn{5}{|l|}{ UM better than ALSWH } \\
\hline Diabetes & 0 & 0.0 & 3.1 & $<.001$ \\
\hline Hypertension & 0 & 0.0 & 19.2 & $<.001$ \\
\hline Thrombosis & 2 & 0.7 & 4.5 & $<.001$ \\
\hline
\end{tabular}

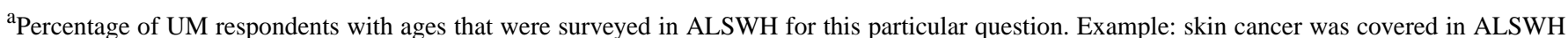
Mid 1 (45-50 years old) and Old 1 (73-78 years old) surveys; UM group had 69 respondents aged 45-50 years and 6 aged 73-78 years who gave valid responses; 4 of the $69+6=75$ had skin cancer.

${ }^{\mathrm{b}}$ ALSWH percentages with UM group frequency weights.

Figure 3. Differences in symptoms between women participating in Universal Medicine (UM) and respondents to the Australian Longitudinal Study on Women's Health (ALSWH). All $P$ values <.001.

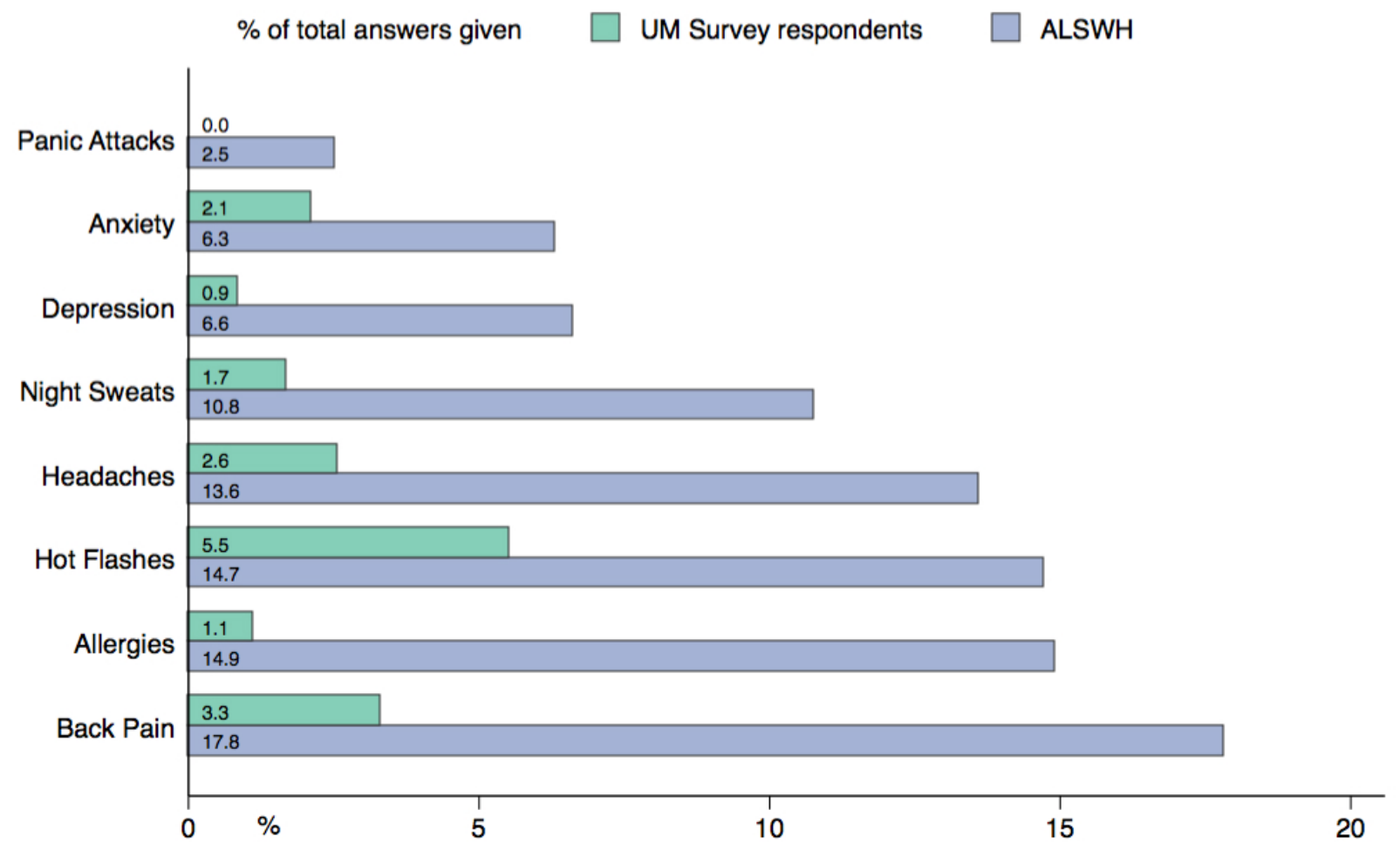


Figure 4. Differences in composite health indicators (36-Item Short Form Survey, SF-36) between women participating in Universal Medicine (UM) and respondents to the Australian Longitudinal Study on Women's Health (ALSWH). Weighted responses; all scores are normalized to mean 50, standard deviation 10 .

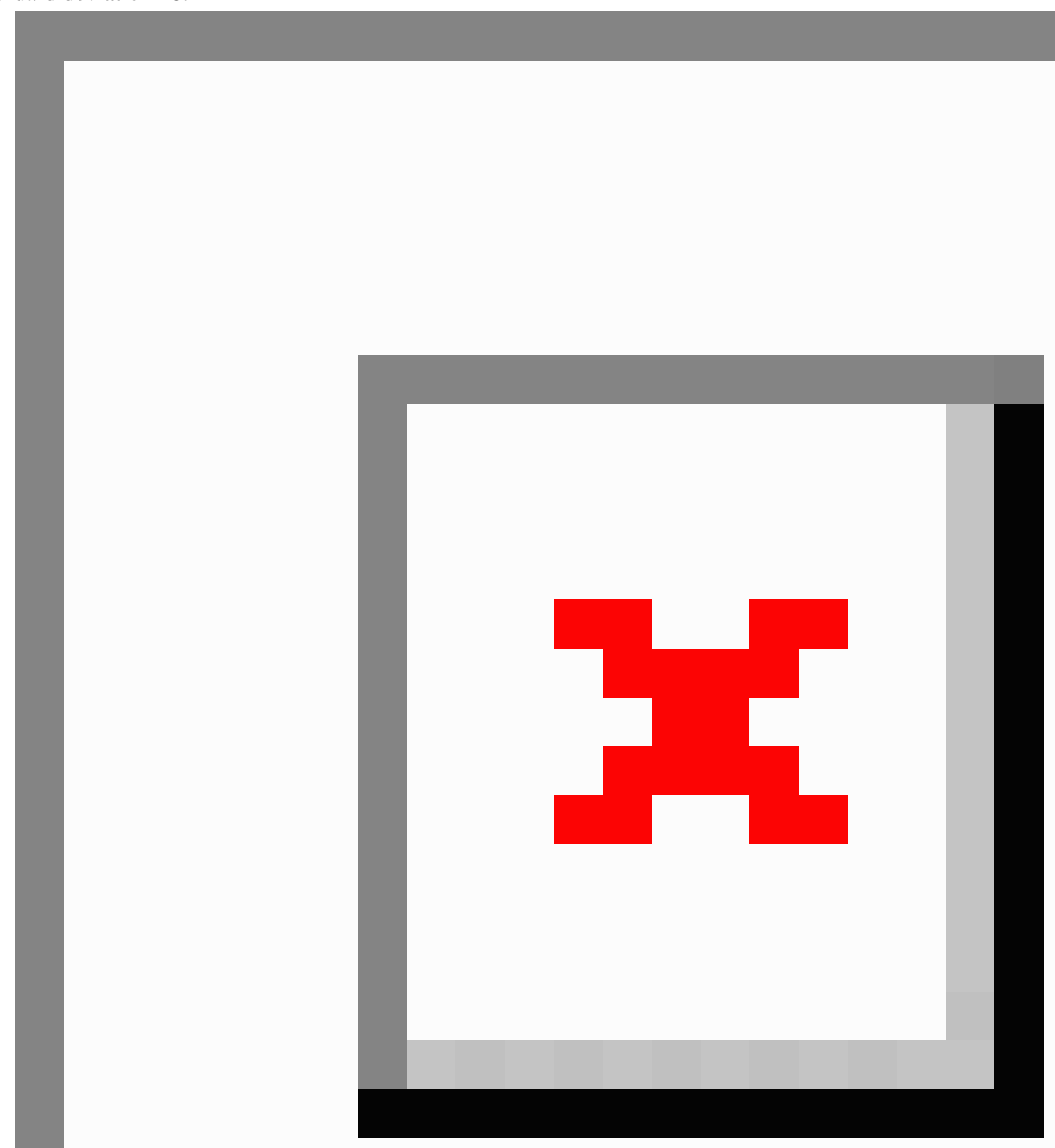

\section{Discussion}

The results from this survey suggest that on several health indicators this group of women was faring notably differently from, and from looking at the data, better than, the general population, as represented by the ALSWH respondents. UM respondents differed in a variety of aspects of physical and mental health, except for lifetime diagnoses of positive Pap smears and low iron. However, these results should be interpreted with caution, as a cross-sectional survey is not able to establish causality.

\section{Principal Findings}

The results show that the UM participants, who on average were 48 years old and had been associated with UM for 8 years, had a lower BMI than the general population; experienced substantially less frequent back pain, lower stress, and depression scores; and scored higher on general mental and physical health, vitality, and perceived level of control. UM participants also had noticeably lower lifetime diagnoses of hypertension, used less hormone replacement therapy, had fewer sleep issues, and had notably fewer instances of allergies, sinusitis, anxiety, breathing difficulties, panic attacks, headaches, migraines, hot flashes, and night sweats. Major differences in 
lifestyle choices were apparent between the UM participants and the ALSWH population, with very low rates of both alcohol use and smoking in the UM group.

There are other groups that demonstrate aspects of above-average health. What may make it worthwhile to investigate the UM group further is the breadth of health indicators for which their scores are better than those of the general population.

\section{About Universal Medicine}

If it is the case that UM participants are healthier than their population cohorts, and that they were not already healthier when they began participating in UM, this raises the question of whether UM practices or interventions could be responsible for this difference and whether there is any plausible mechanism that could explain UM's effects, if any.

The organization's founder, Serge Benhayon, has described $\mathrm{UM}$ as encompassing the concept:

...that [there] is medicine in responsibility, that there's medicine in caring, that there's medicine in nurturing. There is great medicine in love, there is great medicine in stillness, great medicine in harmony, great medicine in surrender, tenderness, preciousness, that there is medicine in everything. Everything is, in fact, eventually medicine, or bad medicine, if we abuse it.

\section{Study Limitations}

One limitation of the study is that only summary ALSWH data were available for comparison. This precluded a case-control analysis, wherein UM respondents would be individually matched to ALSWH respondents. A second limitation is that the UM sample was self-selected and much smaller than the ALSWH group, although 449 respondents constitutes a large majority of the estimated 500 to 600 eligible UM event visitors (women in 2015 who had participated in at least one UM event). While this study is not able to make causal inferences about UM, it might have served to inform identification of promising variables to include in future studies. A third limitation is the possibility of response bias or memory bias among UM respondents. A fourth limitation is that $17 \%$ of UM respondents dropped out during the survey; however, the dropout population did not differ significantly in their health outcomes from the rest of the respondents.

\section{Future Research}

A future study using regression analysis to uncover the association of lifestyle choices and demographics with physical and mental health may be of value. As mentioned previously, a true longitudinal, controlled study of UM participants would be worthwhile, as it would give a more accurate picture of participants' initial health levels, the type and level of specific UM services they access, and the trajectory of their health changes. Such investigation of dose-response relationships and causal factors could inform development of lifestyle modification programs that individuals could use in concert with medicine.

\section{Conclusions}

UM-participating women appear to be notable in that they exhibit better than average health and are not members as a result of any competitive selection, unlike senior Whitehall public servants, who are selected on a competitive basis; nor are UM-participating women part of a population with a limiting cultural or religious tradition. UM women also come from a wide range of backgrounds, ages, and countries. Identifying a group of women who are not part of the obesity epidemic and measuring their other health indicators may be of use for further research. Therefore, further research on this group of women could be worthwhile.

\section{Acknowledgments}

The researchers thank Editoracle for helpful and constructive editing on an earlier version of the manuscript. There is no external funding. CS used personal funds to gain access to the survey software. There were no other expenses.

\section{Authors' Contributions}

CS and VM convened and ran the informal focus groups. CS wrote most of the paper. EJM and JK contributed substantively to writing the paper. JK was also a member of the focus groups. All authors read and approved the final manuscript.

\section{Conflicts of Interest}

All four authors have varying degrees of association with Universal Medicine and are currently members of the Esoteric Practitioners' Association (EPA) which is the body regulating practitioners who are qualified to practice Universal Medicine modalities.

Universal Medicine has a focus on complementary-to-medicine practices, that aim to support and augment medical treatments. Jane Keep has attended Universal Medicine workshops since October 2003. Jane Keep was a director of Universal Medicine UK until 2013. She is a member of the EPA, and a committee member of the EPA, and has been accredited by the EPA to offer Esoteric Healing Modalities since 2010. From 2009-2012 Jane ran a small clinic in England which offered Universal Medicine healing modalities. Since 2012 Jane has been working in corporates/universities/hospitals and occasionally offered paid private Esoteric Healing sessions, though since 2014 she has offered no paid private Esoteric Healing sessions. She was a contributor to Unimed Living 2013 - 2016. Jane has a PhD which referenced the work of over 300 people including Serge Benhayon.

Eunice Minford is a Consultant General Surgeon, and has trained as an Interfaith Minister and Spiritual Counsellor. She also attended the National University of Ireland and obtained a degree of "Master of Applied Christian Spirituality" studying Sacred 
Esoteric Healing in her thesis. Eunice is also editor of the website "Medicine and Serge Benhayon" and a contributor to that website and to the "Unimed Living" website. She has her own blog "The Soulful Doctor" where she discusses, et al, Universal Medicine. She is also on the EPA professional committee as well as a medical advisor to, and the International Patron of, the EPA. She is a trained esoteric healing practitioner and provides occasional private sessions.

Christoph Schnelle is a financial adviser and has some Universal Medicine associated persons among his client base. Christoph is currently working towards his PhD with The University of Queensland, the subject of which is two randomised controlled trials of Esoteric Connective Tissue Therapy (a Universal Medicine modality) on chronic low back pain and has accumulated case studies as part of this project. Christoph Schnelle's wife, Nicola Lessing, is involved in voluntary activities around producing content for "Unimed Living" and other websites. Nicola is company secretary of Unimed Living and does this in an honorary capacity. She is not a director or shareholder of Unimed Living. She is not employed by Universal Medicine or Unimed Living and does not receive any financial incentives from Universal Medicine or Unimed Living.

Vanessa McHardy is involved in voluntary activities around producing content for "Unimed Living", presenting at a conference on Psychological Well Being in 2013 on the Gold Coast of Australia. She has no other involvement other than what is set out below.

All four authors have experienced substantial health benefits since they started visiting Universal Medicine events. They all have published blogs on Universal Medicine associated websites and all four have commented on other blogs published on those websites.

All four have no financial ties and have received no money from Universal Medicine or its related entities including no reimbursements of expenses. Each one attends more than 10 Universal Medicine events a year and regularly receive treatments from Universal Medicine accredited practitioners.

\section{Multimedia Appendix 1}

Strengthening the Reporting of Observational Studies in Epidemiology (STROBE) checklist.

[PDF File (Adobe PDF File), 53KB-Multimedia Appendix 1]

\section{Multimedia Appendix 2}

Sleep issues, BMI changes, and BMI changes by age.

[PDF File (Adobe PDF File), 252KB-Multimedia Appendix 2]

\section{Multimedia Appendix 3}

Symptoms for which Universal Medicine (UM) respondents fared better than Australian Longitudinal Study on Women's Health (ALSWH) respondents.

[PDF File (Adobe PDF File), 49KB-Multimedia Appendix 3]

\section{Multimedia Appendix 4}

Lack of association between education and other scales.

[PDF File (Adobe PDF File), 444KB-Multimedia Appendix 4]

\section{References}

1. Goss J. Projection of Australian health care expenditure by disease, 2003 to 2033. Health and Welfare Expenditure Series No. 36. Canberra, Australia: Australian Institute of Health and Welfare; 2008 Dec. URL: https://www.aihw.gov.au/getmedia/ 7bfc67e9-8fe8-4637-835d-4f0a02749f9e/pahced03-33.pdf.aspx?inline=true [accessed 2018-01-05] [WebCite Cache ID 6wFdYPiHV]

2. Breyer F, Felder S. Life expectancy and health care expenditures: a new calculation for Germany using the costs of dying. Health Policy 2006 Jan;75(2):178-186. [doi: 10.1016/j.healthpol.2005.03.011] [Medline: 15893848]

3. Berwick DM, Hackbarth AD. Eliminating waste in US health care. JAMA 2012 Apr 11;307(14):1513-1516. [doi: 10.1001/jama.2012.362] [Medline: 22419800]

4. Sisko AM, Keehan SP, Cuckler GA, Madison AJ, Smith SD, Wolfe CJ, et al. National health expenditure projections, 2013-23: faster growth expected with expanded coverage and improving economy. Health Aff (Millwood) 2014 Oct;33(10):1841-1850 [FREE Full text] [doi: 10.1377/hlthaff.2014.0560] [Medline: 25187525]

5. Wang Y, Beydoun MA, Liang L, Caballero B, Kumanyika SK. Will all Americans become overweight or obese? Estimating the progression and cost of the US obesity epidemic. Obesity (Silver Spring) 2008 Oct;16(10):2323-2330 [FREE Full text] [doi: 10.1038/oby.2008.351] [Medline: 18719634] 
6. Bagust A, Hopkinson PK, Maslove L, Currie CJ. The projected health care burden of type 2 diabetes in the UK from 2000 to 2060. Diabet Med 2002 Jul;19 Suppl 4:1-5. [Medline: 12121330]

7. Boyle JP, Thompson TJ, Gregg EW, Barker LE, Williamson DF. Projection of the year 2050 burden of diabetes in the US adult population: dynamic modeling of incidence, mortality, and prediabetes prevalence. Popul Health Metr 2010 Oct 22;8:29 [FREE Full text] [doi: 10.1186/1478-7954-8-29] [Medline: 20969750]

8. Wild S, Roglic G, Green A, Sicree R, King H. Global prevalence of diabetes: estimates for the year 2000 and projections for 2030. Diabetes Care 2004 May;27(5):1047-1053. [Medline: 15111519]

9. Egolf B, Lasker J, Wolf S, Potvin L. The Roseto effect: a 50-year comparison of mortality rates. Am J Public Health 1992 Aug;82(8):1089-1092. [doi: 10.2105/AJPH.82.8.1089] [Medline: 1636828]

10. Fraser G. Diet, Life Expectancy, and Chronic Disease: Studies of Seventh-Day Adventists and Other Vegetarians. New York, NY: Oxford University Press; May 2003:1-371.

11. Marmot MG, Syme SL, Kagan A, Kato H, Cohen JB, Belsky J. Epidemiologic studies of coronary heart disease and stroke in Japanese men living in Japan, Hawaii and California: prevalence of coronary and hypertensive heart disease and associated risk factors. Am J Epidemiol 1975 Dec;102(6):514-525. [Medline: 1202953 ]

12. Marmot MG, Smith GD, Stansfeld S, Patel C, North F, Head J, et al. Health inequalities among British civil servants: the Whitehall II study. Lancet 1991 Jun 08;337(8754):1387-1393. [Medline: 1674771]

13. Williams JS, Cunich M, Byles J. The impact of socioeconomic status on changes in the general and mental health of women over time: evidence from a longitudinal study of Australian women. Int J Equity Health 2013 Apr 09;12:25 [ㅍREE Full text] [doi: 10.1186/1475-9276-12-25] [Medline: 23570377]

14. Harris ML, Loxton D, Sibbritt DW, Byles JE. The influence of perceived stress on the onset of arthritis in women: findings from the Australian Longitudinal Study on Women's Health. Ann Behav Med 2013 Aug;46(1):9-18. [doi:

10.1007/s12160-013-9478-6] [Medline: 23436274]

15. Rienks J, Dobson AJ, Mishra GD. Mediterranean dietary pattern and prevalence and incidence of depressive symptoms in mid-aged women: results from a large community-based prospective study. Eur J Clin Nutr 2013 Jan;67(1):75-82. [doi: 10.1038/ejcn.2012.193] [Medline: 23212131]

16. Jackson CA, Mishra GD. Depression and risk of stroke in midaged women: a prospective longitudinal study. Stroke 2013 May 16;44(6):1555-1560. [doi: 10.1161/strokeaha.113.001147]

17. Benhayon S. Universal Medicine. 2000. URL: https://www.universalmedicine.com.au/ [accessed 2018-01-05] [WebCite Cache ID 6wFdeSVwr]

18. Schnelle C, Messerschmidt S, Minford EJ, Greenaway-Twist K, Szramka M, Masiorski M, et al. Esoteric Connective Tissue Therapy for chronic low back pain to reduce pain, and improve functionality and general well-being compared with physiotherapy: study protocol for a randomised controlled trial. Trials 2017 Jul 17;18(1):328-339 [FREE Full text] [doi: 10.1186/s13063-017-2055-8] [Medline: 28716108]

19. McCallum J. Supreme Court of New South Wales judgments. Sydney, Australia: Supreme Court of New South Wales; 2016 Aug 30. Benhayon v Rockett [2016] NSWSC 1210 URL: https://www.caselaw.nsw.gov.au/decision/ 57c4fb60e4b058596cb9ef63 [accessed 2018-01-05] [WebCite Cache ID 6wFtEGqzW]

20. Australian Longitudinal Study of Women's Health. Data books. 2016. URL: http://www.alswh.org.au/for-researchers/data/ data-books [accessed 2017-11-07] [WebCite Cache ID 6un9wE34E]

21. Australian Longitudinal Study of Women's Health. Aims. 2018. URL: http://www.alswh.org.au/about/aims [accessed 2017-08-27] [WebCite Cache ID 6t18wXqQV]

22. Adams J, Sibbritt DW, Easthope G, Young AF. The profile of women who consult alternative health practitioners in Australia. Med J Aust 2003 Sep 15;179(6):297-300. [Medline: 12964912]

23. Hrynaszkiewicz I, Norton ML, Vickers AJ, Altman DG. Preparing raw clinical data for publication: guidance for journal editors, authors, and peer reviewers. BMJ 2010 Jan;340:c181 [FREE Full text] [Medline: 20110312]

24. Ware J, Kosinski M, Gandek B. In: Snow KK, editor. SF-36 Health Survey: Manual \& Interpretation Guide. Lincoln, RI: QualityMetric Incorporated; 1993.

25. Andresen EM, Malmgren JA, Carter WB, Patrick DL. Screening for depression in well older adults: evaluation of a short form of the CES-D (Center for Epidemiologic Studies Depression Scale). Am J Prev Med 1994 Mar;10(2):77-84. [Medline: 8037935]

26. Radloff LS. The CES-D Scale: a self-report depression scale for research in the general population. Appl Psychol Meas 1977 Jun 01;1(3):385-401. [doi: 10.1177/014662167700100306]

27. Bobak M, Pikhart H, Hertzman C, Rose R, Marmot M. Socioeconomic factors, perceived control and self-reported health in Russia. A cross-sectional survey. Soc Sci Med 1998 Jul;47(2):269-279. [doi: 10.1016/S0277-9536(98)00095-1] [Medline: 9720645]

28. Ford J, Lee C. Australian Longitudinal Study of Women's Health. 2004. ALSWH data dictionary supplement, section 2 core survey dataset, 2.7 psychological variables: Perceived Control URL: http://www.alswh.org.au/images/content/pdf/ $\underline{\text { InfoData/Data Dictionary Supplement/DDSSection2PerceivedControl.pdf [accessed 2018-01-06] [WebCite Cache ID }}$ 6unAXdPb1] 
29. Bell S, Lee C. Perceived stress revisited: the Women's Health Australia project young cohort. Psychol Health Med 2003 Aug;8(3):343-353. [doi: 10.1080/1354850031000135786]

30. Rosnow RL, Rosenthal R. Computing contrasts, effect sizes, and counternulls on other people's published data: general procedures for research consumers. Psychol Methods 1996;1(4):331-340. [doi: 10.1037/1082-989X.1.4.331]

31. Benhayon S. Introduction to the day. 2013 Presented at: Sacred Esoteric Healing Level 4, Day 2; Dec 2013; Lennox Head, NSW, Australia.

32. Nakagawa S, Cuthill IC. Effect size, confidence interval and statistical significance: a practical guide for biologists. Biol Rev Camb Philos Soc 2007 Nov;82(4):591-605. [doi: 10.1111/j.1469-185X.2007.00027.x] [Medline: 17944619 ]

33. Cooper H. The search for meaningful ways to express the effects of interventions. Child Dev Perspect 2008;2(3):181-186. [doi: $10.1111 /$ j.1750-8606.2008.00063.x]

34. Cohen J. Statistical Power Analysis for the Behavioral Sciences. Hillsdale, NJ: Lawrence Erlbaum Associates; $1988: 25$.

\author{
Abbreviations \\ ALSWH: Australian Longitudinal Study on Women's Health \\ BMI: body mass index \\ CES-D: Center for Epidemiologic Studies Depression Scale \\ SD: standard deviation \\ SF-36: $36-$ Item Short Form Survey \\ STROBE: Strengthening the Reporting of Observational Studies in Epidemiology \\ UM: Universal Medicine
}

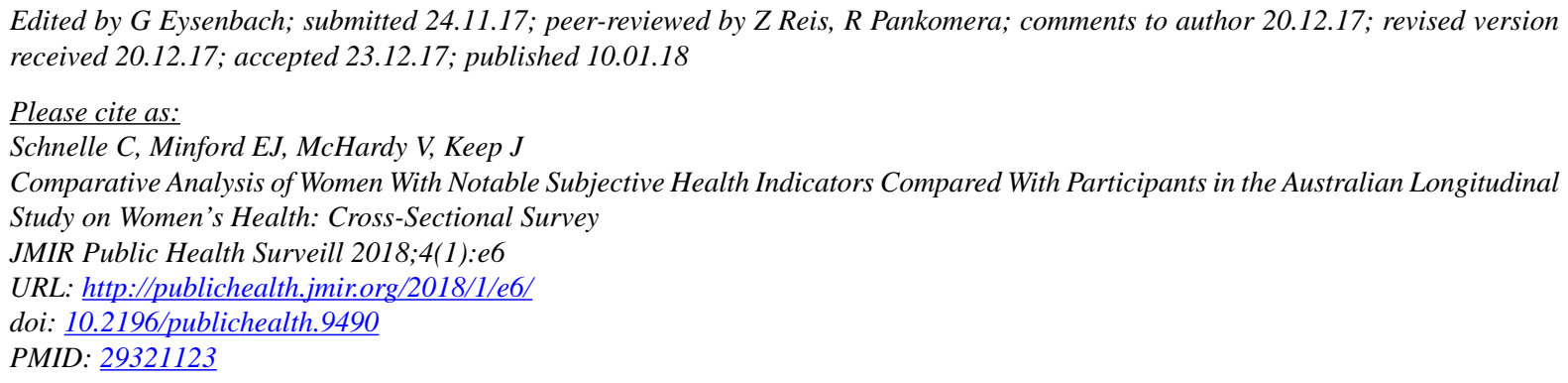

CChristoph Schnelle, Eunice J Minford, Vanessa McHardy, Jane Keep. Originally published in JMIR Public Health and Surveillance (http://publichealth.jmir.org), 10.01.2018. This is an open-access article distributed under the terms of the Creative Commons Attribution License (https://creativecommons.org/licenses/by/4.0/), which permits unrestricted use, distribution, and reproduction in any medium, provided the original work, first published in JMIR Public Health and Surveillance, is properly cited. The complete bibliographic information, a link to the original publication on http://publichealth.jmir.org, as well as this copyright and license information must be included. 